Images dans le monde ibérique et ibéricoaméricain

$8 \mid 2015$

L'Histoire et ses récits entre images, fictions et paratextes

\title{
Mythes et héros de la Révolution mexicaine dans El laberinto de la soledad de Octavio Paz et le muralisme mexicain : un imaginaire collectif
}

\section{Béatrice Ménard}

\section{OpenEdition}

Journals

Édition électronique

URL : http://journals.openedition.org/agedor/328

DOI : 10.4000/agedor.328

ISSN : 2104-3353

Éditeur

Laboratoire LISAA

Référence électronique

Béatrice Ménard, " Mythes et héros de la Révolution mexicaine dans El laberinto de la soledad de Octavio Paz et le muralisme mexicain : un imaginaire collectif », L'Âge d'or [En ligne], 8 | 2015, mis en ligne le 01 février 2016, consulté le 30 avril 2019. URL : http://journals.openedition.org/agedor/328 ; DOI : 10.4000/agedor.328 


\title{
Mythes et héros de la Révolution mexicaine dans $E 1$ laberinto de la soledad de Octavio Paz et le muralisme mexicain : un imaginaire collectif
}

\begin{abstract}
Résumé : Après une présentation du jugement critique porté par Octavio Paz sur le muralisme mexicain à partir de quelques articles de Elprivilegio de la vista, cet article procède à une étude comparée de l'image de la Révolution de 1910 dans El laberinto de la soledad et dans l'œuvre murale de Diego Rivera, José Clemente Orozco et David Alfaro Siqueiros. Il montre comment, tant dans le chapitre VI de l'essai de Paz que dans la sélection de fresques murales analysées, la Révolution apparait comme une rupture historique qui se traduit par une «révélation» de la réalité mexicaine. Il étudie ensuite la représentation des «mythes populaires » associés à la Révolution à partir de la construction des héros révolutionnaires, en particulier Zapata. Il s'interroge enfin sur la représentation de la Révolution comme "fête des balles » dans El laberinto de la soledad et le muralisme mexicain, notamment dans l'œuvre de Orozco.
\end{abstract}

Mots-clés : Révolution - Mexique - Muralisme - Paz- Mythe - Héros - Zapata

Resumen: Tras una presentación del juicio crítico emitido por Octavio Paz sobre el muralismo mexicano a partir de algunos artículos de El privilegio de la vista, este artículo procede a un estudio comparado de la imagen de la Revolución de 1910 en El laberinto de la soledad y en la obra mural de Diego Rivera, José Clemente Orozco y David Alfaro Siqueiros. Muestra cómo, tanto en el capítulo VI del ensayo de Paz como en la selección de murales analizados, la Revolución aparece como una ruptura histórica que se traduce por una «revelación» de la realidad mexicana. Estudia luego la representación de los «mitos populares » asociados a la Revolución a partir de la construcción de los héroes revolucionarios, en particular Zapata. Se interroga por fin sobre la representación de la Revolución como « fiesta de las balas » en El laberinto de la soledad y el muralismo mexicano, especialmente en la obra de Orozco.

Palabras clave: Revolución - México - Muralismo - Paz - Mito - Héroe - Zapata

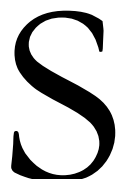

i Octavio Paz accorde peu de lignes au muralisme mexicain dans El laberinto de la soledad, il procède à une analyse critique de ce mouvement pictural dans un article intitulé «Los muralistas a primera vista ». Ce texte, daté de novembre 1950, est contemporain de la première publication de El laberinto de la soledad. Paz y déplore les «ambitions idéologiques » ${ }^{1}$ des muralistes, en particulier celles de Diego Rivera et David Alfaro Siqueiros ; il souligne la contradiction inhérente au fait d'être à la fois « peintre officiel » de l’État mexicain et «artiste révolutionnaire »'. Il reconnait néanmoins le « caractère organique » du muralisme qui lui prête « physionomie, authenticité et grandeur » ${ }^{3}$.

\footnotetext{
1 PAZ, Octavio, "Los muralistas a primera vista », in Los privilegios de la vista II, Arte de México, Obras completas 7 , México, Fondo de Cultura Económica, 1994, p. 185. C’est nous qui traduisons les citations de Paz.

${ }^{2}$ Ibid. : "No se puede ser al mismo tiempo pintor oficial de un régimen y artista revolucionario sin introducir la confusión y el equívoco ».

${ }^{3}$ Ibid. : «La ideología de esta pintura sólo es una cáscara. Si se la aparta, se descubre que es una de las expresiones más altas de nuestra Revolución. Sus mismas limitaciones, su búsqueda de una visión universal que supere nuestras contradicciones, sus deslumbrantes hallazgos son los del movimiento iniciado en 1910. De allí que la pintura mural
} 
Paz développe sa critique du muralisme dans un article publié en 1978 sous la forme d'un dialogue imaginaire intitulé «Re/visiones: la pintura mural». Tout en valorisant la «place unique » qu'occupe le muralisme dans l'histoire de l'art du $\mathrm{XX}^{\mathrm{e}}$ siècle, il dénonce le «culte national $»^{5}$ qui lui est voué : «Los muralistas mexicanos se han convertido en santones. La gente mira sus pinturas como los devotos las imágenes sagradas. ${ }^{6}$ Paz porte un jugement sévère à l'encontre du muralisme dont il condamne les «ambiguités esthétiques et morales ». Il accuse le muralisme d'avoir perdu sa liberté en cédant au dogmatisme politique et en se transformant en art officiel de propagande, au service de l'État issu de la Révolution : " [...] su arte no fue popular sino didáctico; no expresaba al pueblo: se proponía adoctrinarlo. Su interpretación de nuestra historia fue interesada, intolerante, parcial » ${ }^{8}$.

Le jugement porté par Octavio Paz sur le muralisme s’inscrit dans une tradition critique qui remonte aux années vingt et trente et à laquelle participent notamment les membres du groupe Contemporáneos. Xavier Villaurrutia émet ainsi des réserves sur la valeur esthétique de la peinture de Diego Rivera lorsqu'elle se met au service de l'idéologie :

Como obra de propaganda comunista, o lo que sea, puesto que nada es francamente, la obra de Diego Rivera es poco eficaz [...]. El mismo Diego ha comprendido la necesidad de hacer hablar a las figuras de sus cuadros. Y lo hace por ellas como ellas no quisieran hablar, como ellas no hablarían si se les concediera el uso de la palabra - en conferencias, entrevistas y declaraciones a la prensa. Pero la buena pintura no necesita estos artificios. La buena pintura habla sola, a su modo, silenciosamente. ${ }^{9}$

Cette critique du muralisme prend place dans le cadre des polémiques entre nationalistes et universalistes qui enflamment le panorama culturel mexicain après l'arrivée au pouvoir de Plutarco Elías Calles, fin 1924-début 1925, au moment où la politique nationaliste de l'État s'intensifie, jusqu'à sa reconnaissance officielle le 4 mars 1929, lors de la fondation du PNR (Partido Nacional Revolucionario), qui institue la Révolution de 1910 comme la base de la nation mexicaine moderne. On assiste, dès la phase armée de la Révolution mexicaine jusqu'aux années cinquante, à la construction d'un imaginaire collectif qui fait de la Révolution une étape historique décisive dans la prise de conscience de la réalité nationale. L'anthropologue Manuel Gamio affirme en 1916 dans Forjando patria: "La Revolución colabora trascendentalmente [...] a la creación de la futura nacionalidad y al surgimiento de la futura patria mexicana $»{ }^{10}$ Manuel Gómez Morín présente en 1927, dans un essai intitulé 1915, cette année charnière comme celle de la découverte du Mexique en tant que réalité concrète et plurielle :

Y con optimista estupor nos dimos cuenta de insospechadas verdades. Existía México. México como país, con capacidades, con aspiración, con vida, con problemas propios. [...] Y los indios y los mestizos y los criollos, realidades vivas, hombres con todos los atributos humanos. [...] ¡Existían México y los mexicanos!11

Les philosophes de la mexicanité interprètent la Révolution comme une rupture historique essentielle à la connaissance de l'être mexicain. Ainsi Leopoldo Zea en 1952, dans

posea, a su manera, un carácter orgánico. Y ese carácter, más que sus ambiciones ideológicas, es lo que le otorga fisonomía, autenticidad y grandeza ».

4 PAZ, Octavio, « Re/visiones: la pintura mural », in Los privilegios de la vista II, op. cit., p. 188.

${ }^{5}$ Ibid., p. 201.

${ }^{6}$ Ibid.

${ }^{7}$ Ibid.

${ }^{8}$ Ibid., p. 211.

9 VILLAURRUTIA, Xavier, « Cuidado con la pintura », in Imagen, n¹, México, 23 de julio de 1933, in Obras, México, Fondo de Cultura Económica, 1974, p. 1060-1061.

${ }^{10}$ GAMIO, Manuel, «La lógica de la Revolución », in Forjando patria, México, Porrúa, 1960, p. 169.

${ }^{11}$ GÓMEZ MORÍN, Manuel, 1915, México, Cvltvra, 1927, p. 8. 
Conciencia y posibilidad del mexicano : «La Revolución con su poderosa sacudida, permitió al hombre de México encontrarse a sí mismo. Primero se palpó y se hirió mortalmente; después, se captó intuitivamente por medio del arte y ahora trata de hacerse consciente por medio de la reflexión. $»^{12}$ Zea souligne la "force expressive $»^{13}$ de la Révolution mexicaine qui nourrit la pensée politique, philosophique et artistique du pays :

Primero fue la realidad puesta a flote por la violencia revolucionaria, después vino su inspiración y reflexión. Casi a ciegas, tanteando y acariciando una realidad que se presentaba con toda su fuerza sin aviso ninguno, nuestros políticos, pensadores y artistas fueron dibujando sus perfiles. Una realidad, oculta por varios siglos dentro de ropajes que le habían sido ajenos, fue la que dio a estos hombres motivos y materia para su acción, pensamiento e inspiración. ${ }^{14}$

Dans «Los muralistas a primera vista », Paz désigne la peinture murale comme « fille de la Révolution mexicaine $»^{15}$, mettant ainsi l'accent sur le lien de filiation qui les unit. La Révolution de 1910 a une influence décisive sur l'apparition du muralisme, qui s'inscrit dans le cadre de la politique éducative et culturelle de José Vasconcelos, Ministre de l'Éducation Publique d'Álvaro Obregón de 1921 à 1924. Dès 1922, Vasconcelos engage les peintres, tels des fonctionnaires au service de l'État, pour peindre les murs des édifices publics dans l'objectif d'éduquer le peuple. La Révolution mexicaine devient l'un des thèmes de prédilection des peintres, traité par José Clemente Orozco dans l'un des berceaux de la peinture murale, la Escuela Nacional Preparatoria (ou Antiguo Colegio San Ildefonso) en 1926, et par Diego Rivera entre 1923 et 1928 dans la Cour du Travail et la Cour des Fêtes de la Secretaría de Educación Pública, puis tout au long de la carrière picturale d'Orozco, Rivera et Siqueiros, tant au Mexique qu'aux États-Unis.

Dans «Los muralistas a primera vista », Paz définit le muralisme comme «la pintura de un pueblo que acaba de descubrirse a sí mismo ${ }^{16}$, ce qui entre en résonance avec son analyse critique de la Révolution mexicaine dans le chapitre VI de El laberinto de la soledad, intitulé «De la Independencia a la Revolución ». À la fin de ce chapitre, Paz interprète la Révolution en termes de révélation identitaire : «La Revolución mexicana es un hecho que irrumpe en nuestra historia como una verdadera revelación de nuestro ser. $»^{17}$; «La Revolución es una súbita inmersión de México en su propio ser. $»^{18} \mathrm{Il}$ métaphorise la reconnaissance des racines indigènes comme un " retour à la mère ${ }^{19}$, par opposition avec la Réforme, conçue comme un "matricide ${ }^{20}$, par sa négation des origines indigènes du peuple mexicain.

Or, les muralistes représentent cette réalité nationale tout juste découverte en choisissant comme matière première, ainsi que l'écrit Paz, «México, su historia y su paisaje, sus héroes y su pueblo, su pasado y su futuro $»^{21}$, donnant ainsi une réalité esthétique au Mexique. Le manifeste Tres llamamientos de orientación actual a los pintores y escultores de la nueva generación americana, publié en 1921 à Barcelone par David Alfaro Siqueiros, réclame une mexicanisation de la peinture s'appuyant sur une réhabilitation de l'art précolombien. Les fresques murales peintes par Diego Rivera au premier étage du Palacio Nacional entre 1942 y 1951 sont significatives de ce « retour

\footnotetext{
12 ZEA, Leopoldo, «La Revolución como conciencia de México », in Conciencia y posibilidad del mexicano, México, Porrúa, 1974, p. 19.

${ }^{13}$ Ibid., p. 15 : «La Revolución no fue preparada por políticos, pensadores o artistas, sino que ella fue la que con su fuerza expresiva hizo posible a éstos ».

${ }^{14}$ Ibid.

15 PAZ, Octavio, « Los muralistas a primera vista » in Los privilegios de la vista II, op. cit., p. 183.

${ }^{16}$ Ibid., p. 184.

${ }^{17}$ PAZ, Octavio, El laberinto de la soledad, ed. de Enrico Mario Santí, Madrid, Cátedra, 2004, p. 279-280.

${ }^{18}$ Ibid., p. 293.

19 Ibid., p. 293-294: «Vuelta a la tradición, reanudación de los lazos con el pasado, rotos por la Reforma y la Dictadura, la Revolución es una búsqueda de nosotros mismos y un regreso a la madre ».

${ }^{20}$ Ibid., p. 270.

${ }^{21}$ PAZ, Octavio, «Los muralistas a primera vista », in Los privilegios de la vista II, op. cit., p. 183.
} 
aux origines $»^{22}$ par l'interprétation personnelle du passé préhispanique qu'en donne le peintre. Rivera y représente les différentes civilisations précortésiennes (tarasca, zapoteca, totonaca...) de façon harmonieuse, avec une palette chromatique riche et lumineuse, comme l'origine de la construction de la nation et de la formation de l'identité mexicaine.

Le muralisme rompt avec la tradition académique en faisant du peuple mexicain, incarné par l'Indien, le personnage central des fresques, représenté dans ses fêtes rituelles, dans ses luttes sociales et sur son lieu de travail. Le « retour à la mère » se traduit par l'orientation de la peinture murale vers des thèmes nationaux, scènes de genre populaires et scènes de la vie quotidienne, comme celles dont Rivera décore la Cour du Travail et la Cour des Fêtes de la Secretaría de Educación Pública. Citons pour exemple Día de muertos (1923-1924) où Rivera, avec un goût marqué pour les arts populaires, représente la fête des morts dont Paz tente de révéler le sens profond dans le chapitre III de El laberinto de la soledad. Sur ces fresques, qui correspondent à la première étape du muralisme, les Mexicains apparaissent comme un "peuple rituel», qui a conservé «intact» ${ }^{23}$ l'art de la fête, comme l'expose Paz au début de «Todos Santos, día de muertos ", sans que cette représentation de la Fête équivaille pour autant à l'explosion qu'elle signifie dans El laberinto de la soledad.

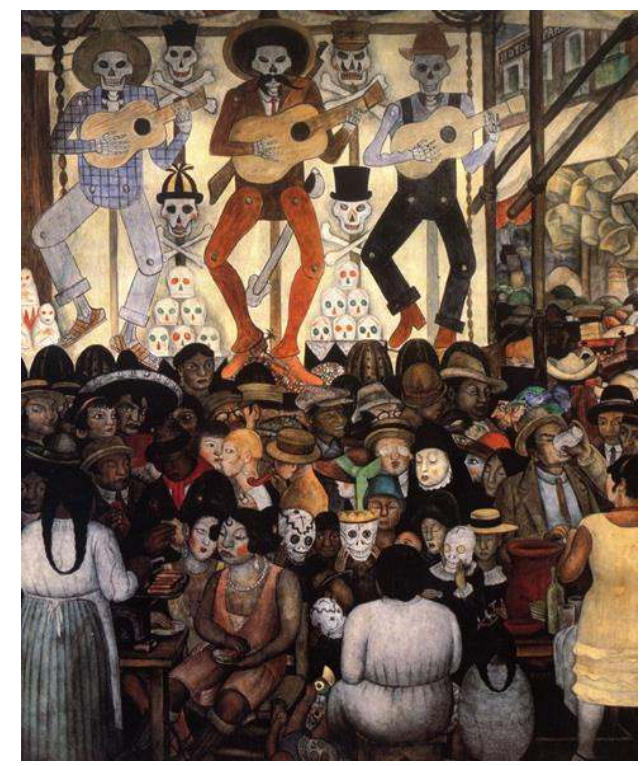

Diego Rivera, Día de muertos, Secretaría de Educación Pública, Cour des Fêtes, 1923-1924

Dans La Destrucción del viejo orden (Escuela Nacional Preparatoria, 1926), Orozco s'inspire de l'esthétique cubiste pour figurer, grâce à la décomposition des plans et aux fractures de la composition créées par l'entrecroisement de lignes droites et courbes discontinues, la rupture de la Révolution avec le vieil ordre oppresseur symbolisé, au second plan, dans la partie supérieure de la peinture murale, par le chaos architectonique des édifices en ruines. Les deux figures masculines stylisées du premier plan jettent un dernier regard en arrière mais leur corps est résolument tourné vers l'avant. La position des personnages, qui forment deux lignes verticales symétriques autour de l'axe central de la fresque, leur accorde une stabilité qui contraste avec le déséquilibre dynamique des vestiges du Porfiriat.

\footnotetext{
22 Ibid., p. 187.

${ }^{23}$ PAZ, Octavio, El laberinto de la soledad, op. cit., p. 182 : «Somos un pueblo ritual. [...] El arte de la Fiesta, envilecido en casi todas partes, se conserva intacto entre nosotros ».
} 


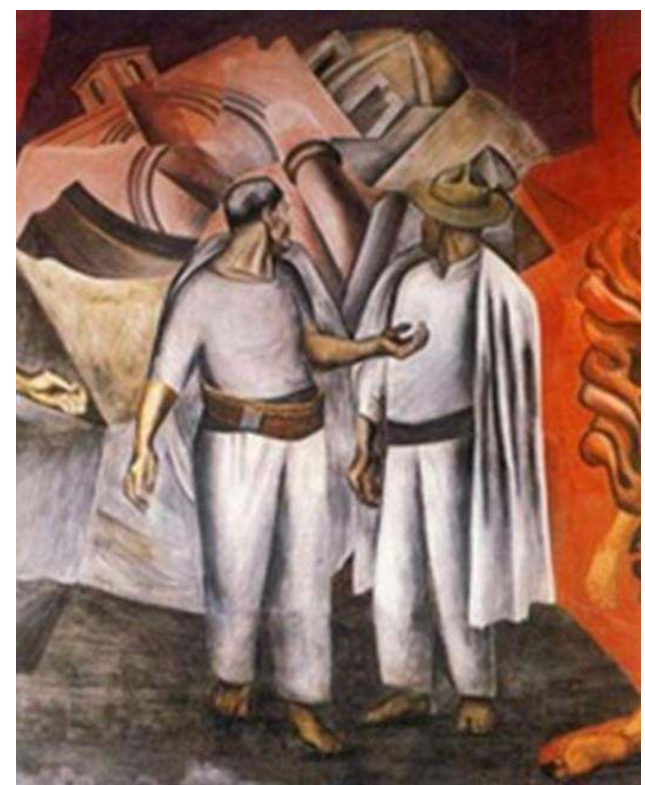

José Clemente Orozco, La Destrucción del viejo orden, Escuela Nacional Preparatoria, 1926

Le symbolisme du vêtement blanc, du chapeau et de la cartouchière se retrouve dans de nombreuses fresques pour figurer le paysan en lutte, aux côtés de l'ouvrier et du soldat de la Révolution. Cette trinité révolutionnaire apparaitt unie dans une relation solidaire dans Triunfo de la Revolución de Diego Rivera (Escuela Nacional de Agricultura, Chapingo, 1926), dernier panneau de la Trilogía de la Revolución, où elle se partage les fruits de la terre. Alors que Paz prête davantage attention à la question agraire qu'à la question ouvrière ${ }^{24}$ dans sa réflexion sur la Révolution mexicaine, Rivera fait converger lutte agraire et lutte ouvrière en représentant sur les murs de la Escuela Nacional de Agricultura et sur ceux de la Secretaría de Educación Pública la fraternelle poignée de mains du paysan et de l'ouvrier ${ }^{25}$, et en réunissant au deuxième étage de la Cour des Fêtes de la SEP le Corrido de la Revolución agraria et le Corrido de la Revolución proletaria (1928-1929).

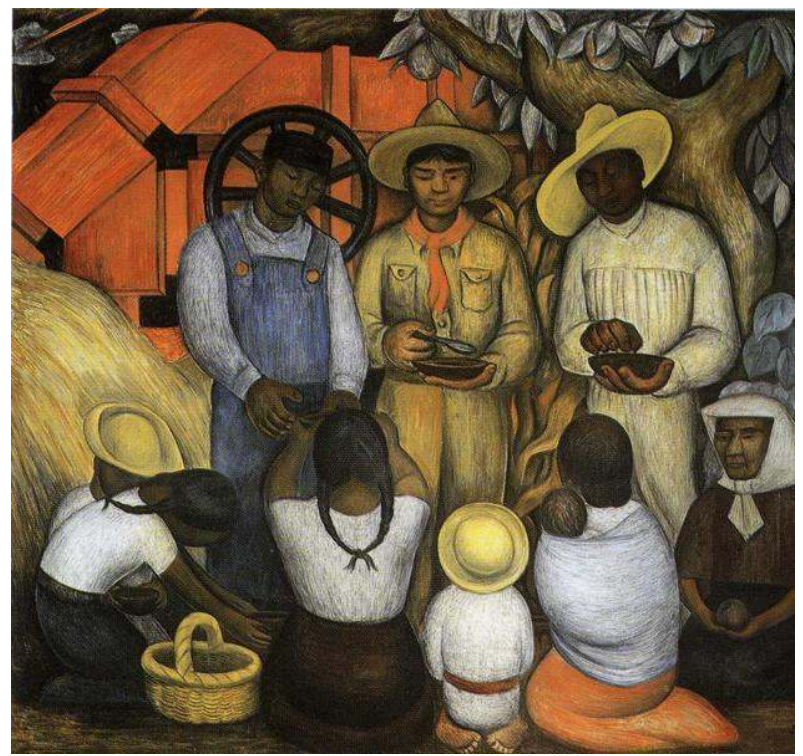

Diego Rivera, Triunfo de la Revolución, Escuela Nacional de Agricultura, Chapingo, 1926

\footnotetext{
${ }^{24}$ Cf. ibid., p. 282.

${ }^{25}$ Fraternidad (SEP, 1923) et El espiritu de la Revolución (Chapingo, 1923-1924)
} 
La représentation iconographique tendant à l'abstraction du "peuple en armes», déformée par le mouvement sous l'influence de l'esthétique futuriste, dans la fresque de Siqueiros Del porfirismo a la Revolución (Castillo de Chapultepec, 1957-1965), est celle d'un personnage collectif dont la force tellurique est exprimée par la chaleur des couleurs ocre-jaune et rouge. Siqueiros met en scène une masse humaine anonyme, au milieu de laquelle on peut reconnaitre Emiliano Zapata. Cette masse compacte et dynamique fait des troupes révolutionnaires en armes le symbole de la renaissance nationale. La soldadera vêtue de rouge représente l'allégorie de la nation en flammes ${ }^{26}$ qui guide le peuple dans sa marche sociale. Celle-ci correspond à une étape fondamentale de la « marche de l'Humanité » ${ }^{27}$, en route vers le progrès.

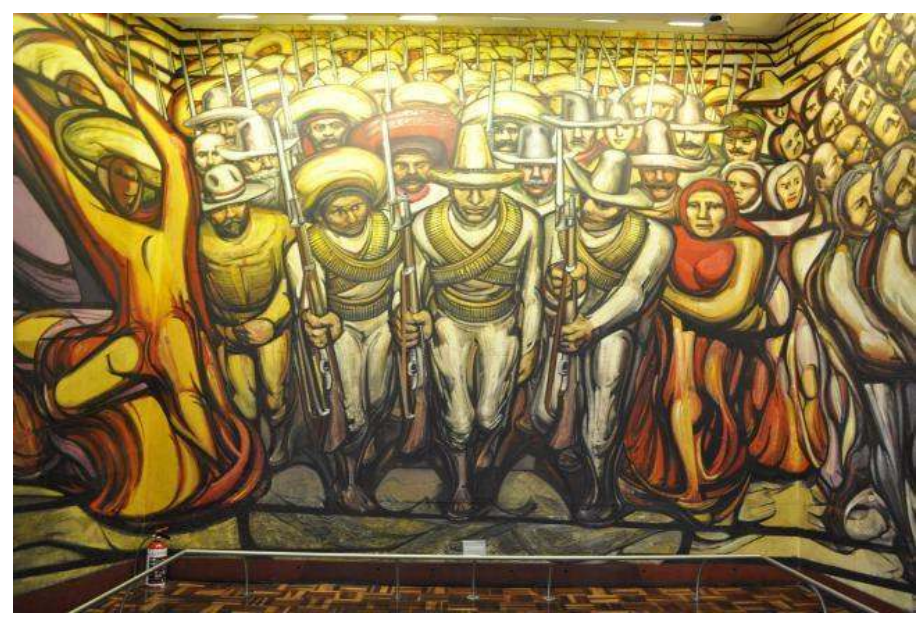

David Alfaro Siqueiros, Del porfirismo a la Revolución, El pueblo en armas, Castillo de Chapultepec, 1957-1966

Dans le chapitre VI de El laberinto de la soledad, Paz représente la figure historique de Zapata comme celle d'un héros où se fondent « réalisme et mythe ${ }^{28}$, dans une belle union des contraires. Ce dirigeant agraire de l'état de Morelos incarne la Révolution populaire et paysanne, associée au slogan "Tierra y libertad», qui apparait sur des drapeaux ou banderoles dans plusieurs œuvres murales de Rivera ${ }^{29}$. Le Plan d'Ayala $(25$ novembre 1911) réclame la restitution des terres usurpées aux communautés indigènes sous l'effet de la loi Lerdo (26 juin 1856) et la distribution des terres non cultivées aux paysans. Zapata est donc indissociable de la reconnaissance de la question agraire et de l'inscription du droit à la terre dans l'article 27 de la Constitution de 1917.

Par le biais de la pensée dialectique qui est la sienne, Paz souligne l'essence paradoxale du zapatisme qui tire son pouvoir de subversion de son traditionalisme. Le programme agraire de Zapata "[abre] la puerta al México contemporáneo $»^{30}$ en rompant avec la politique agraire du Porfiriat. Il est en même temps un « retour aux origines » ${ }^{31}$, c'est-à-dire au « passé indigène » ${ }^{32}$, par son projet de restitution et d'extension de la propriété communale. Paz interprète la Révolution zapatiste comme une aspiration à un mythique "âge d'or»" communautaire. Il conçoit le zapatisme comme «la verdad de México ${ }^{34}$ dans la mesure où, en récupérant le passé mythique,

\footnotetext{
${ }^{26}$ Cette métaphore de la Révolution apparaît également dans le titre du recueil de nouvelles de Juan Rulfo El llano en llamas (1953).

${ }^{27} \mathrm{Il}$ s'agit du titre de la dernière fresque de Siqueiros : La marcha de la Humanidad, Polyforum Siqueiros, 1971.

${ }^{28}$ PAZ, Octavio, El laberinto de la soledad, op. cit., p. 287.

${ }^{29}$ Par exemple dans Sueño de una tarde dominical en la Alameda (1947-1948).

${ }^{30}$ PAZ, Octavio, El laberinto de la soledad, op. cit., p. 287.

${ }^{31}$ Ibid., p. 289.

32 Ibid.

${ }^{3}$ Ibid., p. 288.

34 PAZ, Octavio, «Vuelta a El laberinto de la soledad. Conversación con Claude Fell », in El laberinto de la soledad, op. cit., p. 427.
} 
compris comme « resurrección de lo más antiguo » ${ }^{35}$, Zapata met fin à l'inauthenticité historique de la Réforme et du Porfiriat.

Paz élabore la figure héroïque de Zapata ${ }^{36}$ en l'identifiant à l'archétype de la Terre-Mère, grâce à une longue énumération de style binaire qui le lie au cycle de la nature par allusion au mythème ${ }^{37}$ mort-renaissance : « [...] murió como había vivido: abrazado a la tierra. Como ella, está hecho de paciencia y fecundidad, de silencio y esperanza, de muerte y resurrección $»^{38}$. Le portrait futuriste du Revolucionario a caballo peint par Siqueiros sur le mur latéral au panneau qui représente les martyrs de la Révolution dans Del porfirismo a la Revolución nous parait également évoquer le mythème mort-renaissance. La force d'impulsion du cheval au galop, qui ne fait qu'un avec son cavalier, représenté sur un fond aux couleurs rouges éclatantes, acquiert un puissant symbolisme vital qui, par l'impression de vitesse qui s'en dégage, semble triompher de la mort. Le sacrifice des martyrs de la Révolution n'est pas vain puisque le cheval et son cavalier en tirent force dans leur course vers le progrès.

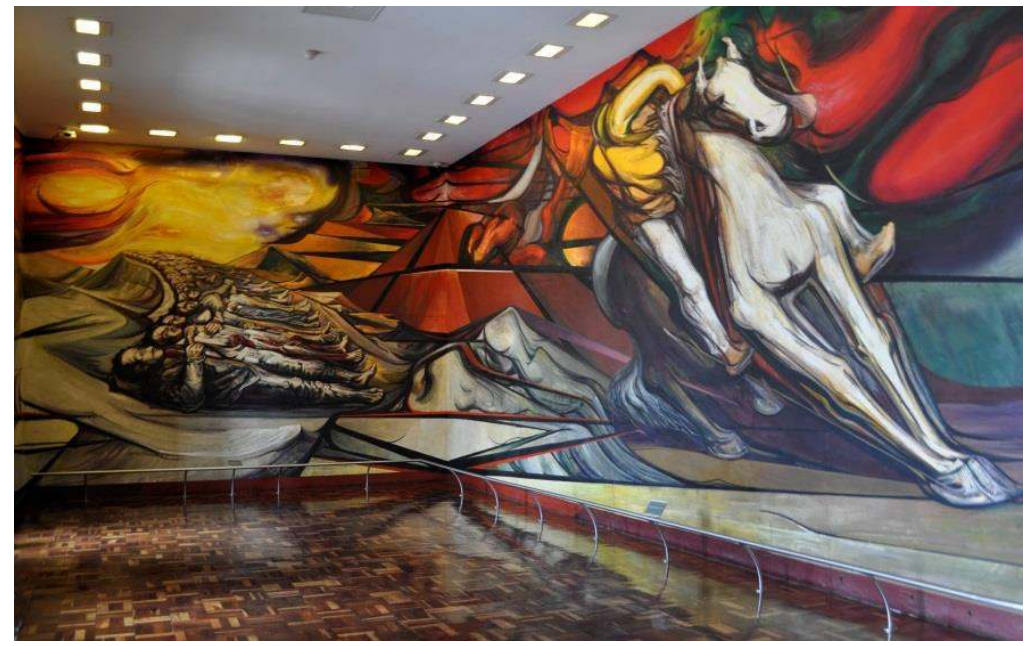

David Alfaro Siqueiros, Del porfirismo a la Revolución, Revolucionario a caballo, Castillo de Chapultepec, 19571966

La fresque de Diego Rivera La continua renovación de la lucha revolucionaria ${ }^{39}$ (Escuela Nacional de Agricultura, Chapingo, 1926-1927) symbolise le cycle de la terre évoqué par Paz. Cette fresque agraire représente un groupe de révolutionnaires zapatistes veillant l'un de leur camarade tué au combat, au pied d'un arbre au tronc vigoureux. Rivera peint la lutte paysanne pour la récupération de la terre, inséparable de l'identité indigène comme le suggère la superposition des visages bruns sur la terre marron qui donne son caractère tellurique à la composition. Le titre exprime l'idée de renaissance. Mort et vie sont ainsi unies, comme dans le passage d'El laberinto de la soledad que nous venons de citer, par une féconde relation dialectique, car la vie naît de la mort. La fresque tout entière repose sur le mythème mort-renaissance. Cette renaissance est symbolisée par les racines de l'arbre ${ }^{40}$ qui s'enfoncent dans la terre, fertilisée par le

\footnotetext{
${ }^{35}$ KRAUZE, Enrique, TAJONAR, Héctor, «México independiente y contemporáneo: El laberinto de la soledad y el liberalismo (entrevista con Octavio Paz) », in PAZ, Octavio, El laberinto de la soledad, edición conmemorativa 50 aniversario, t. II, México, Fondo de Cultura Económica, 2000, p. 71.

${ }^{36}$ Paz souligne la dimension poétique et plastique de Zapata : « [...] figura que posee la hermosa y plástica poesía de las imágenes populares » (PAZ, Octavio, El laberinto de la soledad, Madrid, Cátedra, 2004, p. 287).

${ }^{37}$ Plus petite unite de signification du mythe.

${ }^{38}$ PAZ, Octavio, El laberinto de la soledad, op. cit., p. 287.

${ }^{39}$ Il s'agit du deuxième panneau de la Trilogía de la Revolución.

${ }^{40}$ L'arbre de vie de La continua renovación de la lucha revolucionaria, qui se nourrit de ceux qui sont morts pour la terre et la liberté, partage un symbolisme commun avec «l'arbre du peuple » évoqué dans le poème qui ouvre le chant IV du Canto general de Pablo Neruda (1950), intitulé «Los libertadores » :
} 
sang du révolutionnaire tué au combat. Les fleurs de l'arbre sont symboliquement rouges, de même que le drapeau, le linceul du paysan zapatiste et le sang qui coule de la bouche du mort. La posture du corps, allongé sur le sol, suggère un fertile échange avec la Terre-Mère, dans un cycle incessant de mort-renaissance. Comme l'explique Raquel Tibol : «[...] la muerte del campesino marca la plena floración del movimiento social [...] aquí la simplificación geométrica tiene un instante de culminación. Sobre la tierra que corre como un río, las formas redondas parecen girar. $»^{41}$

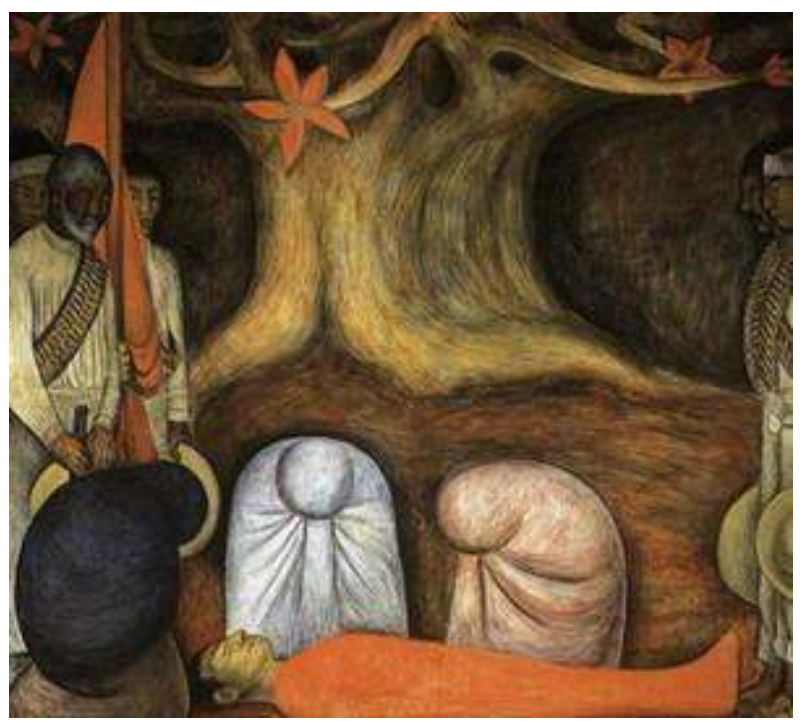

Diego Rivera, La continua renovación de la lucha revolucionaria, Escuela Nacional de Agricultura, Chapingo, 1926-1927

La fresque La sangre de los mártires agrarios, peinte, comme la précédente, dans l'ex-chapelle de la hacienda de Chapingo, confirme ce symbolisme. Y reposent sous la terre les corps d'Emiliano Zapata et d'Otilio Montaño ${ }^{42}$, entourés d'un sarape rouge, alors que le maïs, origine mythique de l'homme américain selon le Popol Vuh, pousse à la surface du sol. Le sang des martyrs agraires fait fructifier la terre, éveillant de puissantes forces souterraines. La fleur rouge peinte autour de la fenêtre, au centre de la composition, symbolise la floraison de l'idéologie marxiste. Le processus historique de la Révolution mexicaine est ainsi symbolisé par le cycle de la terre. Comme le précise Rivera : «El tema alegórico o simbólico [...] permite desprender de la esclavitud exterior el asunto realista y realizar lo necesario, para que de acuerdo con los muros que la sustentan y las fuerzas internas de la arquitectura y las necesidades de luz y sombra de sus accidentes, la pintura decorativa sea en sí misma "verdad". »"

\footnotetext{
Aqui viene el árbol, el árbol

Cuyas raíces están vivas,

Sacó salitre del martirio,

Sus raices comieron sangre

Y extrajo lágrimas del suelo:

Las elevó por sus ramajes,

Las repartió en su arquitectura.

Fueron flores invisibles,

A veces, flores enterradas,

Otras veces iluminaron

Sus pétalos, como planetas.
}

NERUDA, Pablo, Canto general (1950), ed. de Enrico Mario Santí, Cátedra, Madrid, 1992, p. 185.

41 TIBOL, Raquel, Los murales de Diego Rivera, Universidad Autónoma Chapingo, México, Editorial RM, 2002, p. 82.

42 Rivera représente également les martyrs de la Révolution sur les murs de la SEP (Cour du Travail, 1924).

${ }^{43}$ RIVERA, Diego, cité par TIBOL, Raquel in Los murales de Diego Rivera, Universidad Autónoma Chapingo, op. cit., p. 3132. 


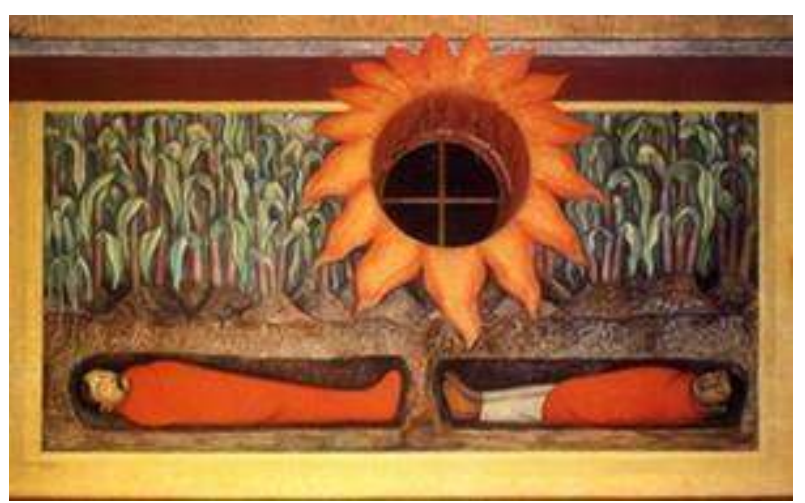

Diego Rivera, La sangre de los mártires agrarios, Escuela Nacional de Agricultura, Chapingo, 1926-1927

Dans le chapitre VI de El laberinto de la soledad, Octavio Paz analyse la façon dont la Révolution marque de son empreinte l'imaginaire collectif mexicain, avec ses multiples facettes antithétiques, incarnées par ses principaux protagonistes, figures à la fois historiques et mythiques, portées par le souffle épique qui les anime :

[...] la brutalidad y zafiedad de muchos de los caudillos revolucionarios no les han impedido convertirse en mitos populares. Villa cabalga todavía en el norte, en canciones y corridos; Zapata muere en cada feria popular; Madero se asoma a los balcones agitando la bandera nacional; Carranza y Obregón viajan aún en aquellos trenes revolucionarios, en un ir y venir por todo el país [...]. Todos los siguen: ¿a dónde? Nadie lo sabe. Es la Revolución, la palabra mágica, la palabra que va a cambiarlo todo y que nos va a dar una alegría inmensa y una muerte rápida. ${ }^{44}$

En assimilant la Révolution à une "fête des balles »", Paz charge cet événement historique de l'ambivalence de la fête mexicaine, tout à la fois mortifère et vitale, dans une explosive fusion des contraires, telle qu'il l'interprète dans le chapitre III de son essai : «Como las fiestas populares, la Revolución es un exceso y un gasto, un llegar a los extremos, un estallido de alegría y desamparo, un grito de orfandad y de júbilo, de suicidio y de vida, todo mezclado ${ }^{46}$. Or, dans «Los muralistas a primera vista » $\mathrm{Paz}$ compare également la peinture d'Orozco à une "explosion ${ }^{47}$, dans laquelle s'exprime «le sarcasme, la dénonciation et la quête ${ }^{48}$ de la Révolution mexicaine. Il met ainsi en valeur la force critique de l'expressionisme d'Orozco, désigné dans «Re/visiones: la pintura mural» comme «le plus rebelle et indépendant ${ }^{49}$ des muralistes. Il oppose la représentation d'une « Révolution triomphante $»^{50}$, qui est celle de Rivera et Siqueiros, à la satire du mouvement révolutionnaire à laquelle se livre l'auteur de La trinchera (Escuela Nacional Preparatoria, 1926).

\footnotetext{
44 PAZ, Octavio, El laberinto de la soledad, op. cit., p. 293.

${ }^{45}$ Ibid., p. 294. Paz emprunte cette expression au chapitre éponyme d'El águila y la serpiente de Martín Luis Guzmán (1928) qui décrit l'exécution en masse de prisonniers par les troupes de Pancho Villa. Les prisonniers doivent traverser une cour, sous la menace des armes, la vie sauve étant promise à ceux qui réussiront à s'échapper. Les soldats villistes tuent tour à tour tous les prisonniers, sauf le dernier qui parvient à se sauver. Tout au long de la scène, la "passion de tuer » des soldats va croissant, s’opposant au « désir de vivre » des prisonniers. Cf. GUZMÁN, Martín Luis, El águila y la serpiente, in CASTRO LEAL, Antonio (ed.), La novela de la Revolución mexicana, t. 1, México, Aguilar, 1960, p. 258-264.

${ }^{46}$ PAZ, Octavio, El laberinto de la soledad, op. cit., p. 294.

47 PAZ, Octavio, «Los muralistas a primera vista » in Los privilegios de la vista II, op. cit., p. 186 : «Su pintura puede parecernos a veces una explosión, pero sabemos que esa explosión es real: quema ».

48 Ibid., p. 187 : «La obra de Orozco completa la de Rivera. Ambas representan los dos momentos de la Revolución mexicana. Rivera la vuelta a los orígenes; Orozco el sarcasmo, la denuncia y la búsqueda ».

49 PAZ, Octavio, « Re/visiones: la pintura mural » in Los privilegios de la vista II, op. cit., p. 201.

${ }^{50}$ Ibid., p. 210 : «La pintura mural mexicana fue ante todo la expresión de una revolución triunfante ».
} 


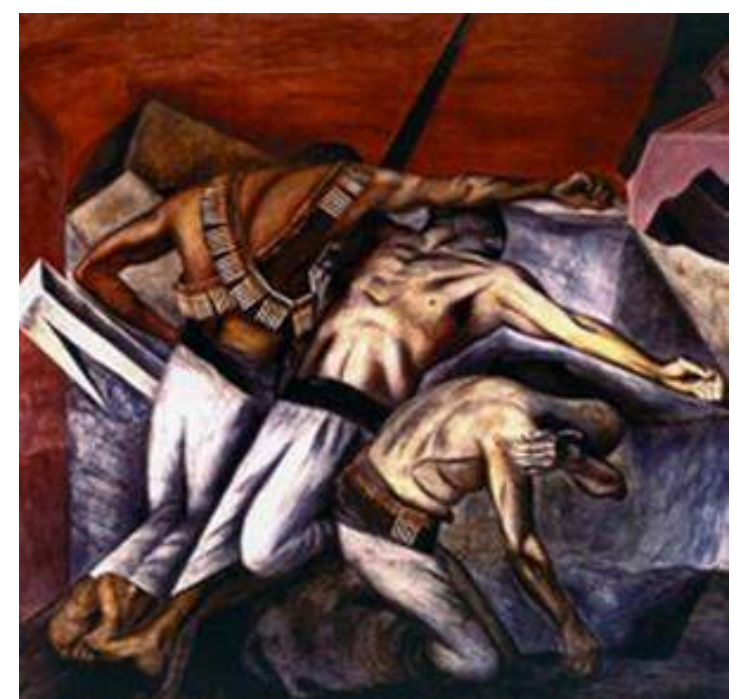

José Clemente Orozco, La trinchera, Escuela Nacional Preparatoria, 1926

Cette fresque tranche par son pessimisme avec l'espoir de rupture exprimé dans La Destrucción del viejo orden. Orozco y donne une vision sombre et tragique de la Révolution mexicaine, où le déséquilibre des diagonales affecte non pas les vestiges du passé mais la représentation des corps des combattants. Ceux-ci semblent figés dans leur mortel affrontement, loin de «l'explosion révolutionnaire » ${ }^{51}$ telle que la définit Paz dans El laberinto de la soledad: « una portentosa fiesta en la que el mexicano, borracho de sí mismo, conoce al fin, en abrazo mortal al otro mexicano $»^{52}$. Nulle communion dans cette lutte fatale qui crucifie les adversaires sans espoir de résurrection, dans une chute qui anéantit le visage de l'autre, rendant impossible toute connaissance de son être. Le visage du soldat de la Révolution armé d'un fusil qui domine la composition triangulaire déséquilibrée de La Trinidad revolucionaria (Escuela Nacional Preparatoria, 1923-1924) est également caché, occulté par le drapeau rouge de la lutte révolutionnaire. Ce drapeau se transforme en bonnet phrygien comme pour mieux dénoncer l'aveuglement idéologique des "faux leaders ${ }^{53}$ dont Orozco condamne la force d'oppression sur le paysan désespéré et l'ouvrier mutilé, aux antipodes de la composition harmonieuse et paisible de la trinité révolutionnaire peinte par Diego Rivera dans Triunfo de la Revolución.

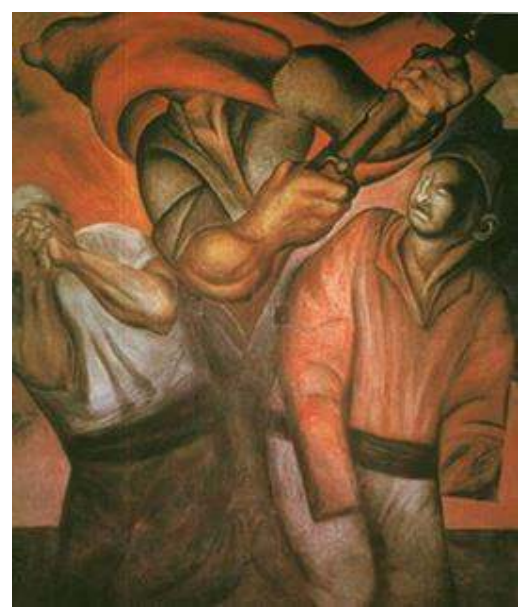

José Clemente Orozco, La trinidad revolucionaria, Escuela Nacional Preparatoria, 1923-1924

\footnotetext{
${ }^{51}$ PAZ, Octavio, El laberinto de la soledad, op. cit., p. 294.

${ }^{52}$ Ibid.

${ }^{53}$ Cf. OROZCO, José Clemente, Elpueblo y los falsos líderes, Universidad de Guadalajara, 1936.
} 
La Révolution de 1910 marque donc le point de départ de la quête artistique et politique des muralistes mexicains. Elle apparaît dans les peintures murales comme un moment décisif de l'Histoire du Mexique et de ses luttes sociales, notamment sur la grande fresque historique peinte par Rivera dans la cage d'escalier du Palacio Nacional (1929-1935) ${ }^{54}$. La représentation de la Révolution sur les murs des édifices publics participe à la création d'une mythologie collective enracinée dans la découverte de la réalité et du peuple mexicains à laquelle contribuent artistes et intellectuels de la première moitié du $\mathrm{XX}^{\mathrm{e}}$ siècle dans leur recherche de l'identité nationale. Comme cela est le cas dans les fresques de Rivera et de Siqueiros que nous venons d'évoquer, le muralisme contribue au mythe hérö̈que de la Révolution par son exaltation de la lutte révolutionnaire et le processus de mythification de ses héros populaires, célèbres et anonymes, Indiens, paysans et ouvriers. La représentation de la Révolution ne s'y confond pas pour autant avec le nationalisme révolutionnaire de l'État mexicain. L'approche personnelle très contrastée, voire contradictoire, que Rivera, Siqueiros et Orozco ont de la Révolution reflète la pluralité esthétique du muralisme et les différences idéologiques qui séparent les trois peintres. La «vision noire $»^{55}$ de la Révolution qui est celle d'Orozco, pour reprendre l'expression de Paz, s'oppose fortement à l'image flamboyante qu'en donne Siqueiros et à l'impression de solidarité populaire qui ressort de la peinture qu'en fait Rivera. L'iconographie symbolique des fresques murales, qui intéresse tout particulièrement Octavio Paz dans la première étape du muralisme, leur donne une dimension universelle en même temps qu'elle devient un instrument de révélation de la réalité mexicaine issue de la Révolution. N’oublions pas que Paz prête au mythe ce même pouvoir de révélation de la réalité : "Y es que el mito no sólo expresa a la realidad; representándola en una acción imaginativa y hermética también la prefigura y la modela; al revelarla, la obliga a seguir los dictados de su misteriosa inspiración: la constriñe a alcanzar las metas que se propone. $»^{56}$

\footnotetext{
${ }^{54}$ Mur nord: México Antiguo (1929). Mur central : De la conquista a 1930 (1929-1931). Mur sud : México de boy y de mañana (1934-1935). Cf. RODRÍGUEZ MORTELLARO, Itzel, «La nación mexicana en los murales del Palacio Nacional (1929-1935) », in RIVERA, Diego, Los murales del Palacio Nacional, México, Instituto Nacional de Bellas Artes, 1997, p. 66 : «Frente a los agraristas, la figura de un obrero, vestido con el overol del trabajo industrial, les indica con el brazo la ruta hacia el muro sur, es decir el futuro ». Ibid., p. 76 : « Hacia la izquierda, la figura de Karl Marx con una leyenda del Manifiesto comunista, muestra a la trinidad revolucionaria (soldado, obrero y campesino) el paisaje de la nueva sociedad progresista que resulta de la revolución socialista, fundada en la industria, la agricultura y la ciencia ».

55 PAZ, Octavio, « Ocultación y descubrimiento de Orozco », in Los privilegios de la vista II, op. cit., p. 242.

56 PAZ, Octavio, "Poesía y mitología, novela y mito », in Miscelánea I, Primeros escritos, Obras completas 13, México, Fondo de Cultura Económica, 1999, p. 232.
} 